\title{
A tale of two doctoral students: social media tools and hybridised identities
}

\author{
Liz Bennett $^{\mathrm{a} *}$ and Sue Folley ${ }^{\mathrm{b}}$ \\ ${ }^{a}$ School of Education and Professional Development, University of Huddersfield, Huddersfield, \\ UK; ${ }^{b}$ Computing \& Library Services, University of Huddersfield, Huddersfield, UK
}

(Received 10 January 2014; final version received 29 April 2014)

This paper explores the experiences of two doctoral students who embraced Web 2.0 tools in their digital scholarship practices. The paper gives an insider perspective of the challenges and potential of working with online tools, such as blogs, and participating in online communities, such as Twitter's \#phdchat. We explore by drawing on our personal experiences as to how this participation was affected by our hybridised identity as both members of staff at a UK university and as PhD students. We argue that social media tools provide access to a community of doctoral students and knowledgeable others that reduce isolation and provide challenge and support along the challenging journey of undertaking a doctoral study. Whilst the tools involved exposure and risk in relation to managing our hybridised identities, our experience of their use was one we would recommend to others.

Keywords: doctoral students; liminality; blogging; Web 2.0; Twitter

\section{Introduction}

This paper is based on the experience of two doctoral students who used social media tools during their doctoral studies between 2007 and 2012. The paper focuses on the nature of doctoral student identity and its development and how using social media tools affect this process. Social media is a loose term for web-based tools that enable users to participate and contribute to knowledge building (Hemsley and Mason 2013; Lewis, Pea, and Rosen 2010; Powell, Jacob, and Chapman 2012). It includes a variety of tools and services including blogs (such as WordPress, Blogger), wikis (such as Wikimedia, pbwiki), social networking tools (such as Facebook, academia. edu), microblogging (such as Twitter, Friendfeed), social bookmarking tools (such as Diigo, Delicious), recommender systems (such as LinkedIn), document sharing (such as Google docs, Scribd, Dropbox) and publication sharing (such as Mendeley, CiteULike). For the purpose of this paper, we focus on two of these social media tools: Twitter and blogging. Both of these tools share common characteristics in that they are generally public, text-based and permanent in nature. These tools provide a new medium for PhD students to enact their scholarship and present themselves and their work to a wide audience. Using these tools invites certain types of behaviours, which carries challenges and risks. The sort of behaviour that is typically evident in Twitter is

*Corresponding author. Email: e.bennett@hud.ac.uk

Research in Learning Technology 2014. (C) 2014 L. Bennett and S. Folley. Research in Learning Technology is the journal of the Association for Learning Technology (ALT), a UK-based professional and scholarly society and membership organisation. ALT is registered charity number 1063519. http://www.alt.ac.uk/. This is an Open Access article distributed under the terms of the Creative Commons CC-BY 4.0 License (http:// creativecommons.org/licenses/by/4.0/), allowing third parties to copy and redistribute the material in any medium or format and to remix, transform, and build upon the material for any purpose, even commercially, provided the original work is properly cited and states its license. 


\section{Bennett and S. Folley}

light-hearted, intimate, conversations that are short and thus quite superficial whereas a blog posting is a longer diary piece, which lends itself to a style of writing that is often more considered and developed.

Both authors were employed in professional roles at a northern UK University during the time of their doctoral studies. This dual identity as both students and members of staff is characterised by managing the conflicting status and identity of being employed in a professional role and being a learner at the same time. Orr and Simmons (2010) similarly discuss the conflicted nature of dual identity in relation to further education trainee teachers who work alongside studying. Recent years have seen a rise in the numbers undertaking professional doctorates (Wikeley and Muschamp 2004). This suggests that the issues of managing one's dual identity are of growing relevance. Our experience may also be relevant to full-time PhD students for whom a $\mathrm{PhD}$ is a route for career development and hence their identity as a student is entwined with their potential to gain employment.

Our discussion is an autoethnographic account based on our insider perspective as users of social media. Autoethnography is an approach where the authors draw on their personal experience to extend understanding of a discipline or culture (Varpio et al. 2012). Autoethnography combines the features of autobiography and ethnography (Ellis, Adams, and Bochner 2010). It differs from autobiography in that in addition to writing about their own experiences, the authors extend their analysis through building on the literature and theory. Ellis, Adams, and Bochner (2010) suggest that autoethnographers 'must use personal experience to illustrate facets of cultural experience, and, in so doing, make characteristics of a culture familiar for insiders and outsiders. To accomplish this might require comparing and contrasting personal experience against existing research' (Section 2, para 5). Autoethnographers argue that insider accounts provide insights into the phenomena and group dynamics that others outside that culture cannot observe (Vickers 2002). Learmonth and Humphreys (2012) suggest that autoethnographic accounts are able to provide scholars with new forms of empirical material, namely in this paper, a discussion of the nature of identity work and social media. An autoethnographic approach is particularly appropriate to understanding social media tools because it enables an exploration of the complexity of practices from the perspective of an active participant (Veletsianos 2013). The main limitation of autoethnography is that, by definition, the accounts are personal and thus may not be representative of a wider audience. Instead, the personal conclusions enable others to consider their own actions and experiences and to compare them to those of the authors in addition to learning about unfamiliar people or cultures (Ellis 2004).

The focus for our autoethnography is the use of social media during our doctoral studies. Our adoption of social media started around 2007 and was driven by our professional roles - Sue as an Academic Developer and Liz as Course Leader of a Master's programme in e-learning. We wanted to gain a first-hand understanding of their potential to apply to our professional roles; however, our use of social media tools extended beyond our professional roles to using them to support our $\mathrm{PhD}$ studies, and it is this aspect that is the focus for this paper. Our doctoral studies started in September 2007 and we finished in mid- to late 2012. This paper has been written by drawing principally on our memory supplemented by some other evidence including archives of the \#phchat conversations and our research diary entries. It was written in 2013, soon after we had completed our studies. 
During the time of our doctoral studies, the tools that we focus on were embryonic: Twitter, in particular, grew from its launch in 2006 to having a millions of users in 2012. Their use is under-explored and literature on social media practices in higher education is often accompanied by calls for more research in this area (Beldarrain 2006; GannonLeary, Fontainha, and Bent 2011; Gu and Widén-Wulff 2011; Kirkup 2010; Mewburn and Thomson 2013; Veletsianos 2012, 2013; Ward and West 2008). Thus, this paper seeks to explore this emergent area. Our focus is on the formation of our doctoral identity through the use of social media practices. It is structured around three themes: the notion of doctoral students as having a hybridised identity, a discussion of the doctoral journey as a transition process, and, finally, working practices associated with social media. The paper describes our experiences of these new and developing set of practices and analyses how using these social media tools during our doctoral studies affected us.

\section{Hybridised identity}

Hybridised identity is the notion of the multiple roles that individuals inhabit, for instance as a subject expert, teacher, student and a budding researcher. Beijaard, Meijer, and Verloop (2004) suggest that a person's identity is not fixed but relational, in that it changes in different contexts. Thus, as academic staff undertaking a doctorate, we experienced the challenge of managing these contrasting aspects of our identity as conflicted and complex because we identified both as an expert and novice. We were both employed in professional jobs, premised on our expertise, yet we experienced undertaking doctoral study by positioning ourselves as novices, and we felt academically challenged. Pilkington (2009) similarly reported that teachers on a professional doctorate programme experienced their academic study as returning them to the status of a novice in relation to learning about undertaking research after the experience of being the one in control in relation to their professional role:

As a teacher you play a role which is all-seeing and all-knowing. When you move into research it is very hard to separate this perspective from your study and it really takes some time to acquire the disciplines of research and rid yourself of this subjective allknowing role. (p. 164)

We experienced this tension of feeling like a novice and an expert at the same time, as heightened by our use of the social media. The online world provides a place in which these different identities are less separated than in the offline world. On Twitter, an academic member of staff who is studying for a $\mathrm{PhD}$ can be followed by other experts in their field, academic colleagues, other PhD students, potential examiners, their own students, and friends and family. The identity we portrayed related to a combination of all these roles and relationships, making for a complex sense of our online identity. In practice, this meant that tweets written with one audience in mind, such as our work colleagues, were also being read by the other audiences, such as our students or our friends. We could have managed this situation by having more than one Twitter account, each used for different purposes, but neither of us did so, and used just one Twitter account for professional, PhD-related and social tweets. This was, in part for ease, as managing multiple accounts for different purposes would be more time consuming, but partly because we wanted people to be aware of our various identities and to connect on a personal level alongside the professional and academic. 


\section{Bennett and S. Folley}

The need to build a social presence in the online environments is advocated by Garrison, Anderson, and Archer (2000) who suggested that for a successful online educational experience there should be three types of presence demonstrated, namely 'teacher presence', 'cognitive presence' and 'social presence'. They argue that students need to have ways to connect socially and intellectually online in order to engage in meaningful dialogue. Twitter provided us with this mechanism as it facilitated and supported the integration of the social with the academic. Indeed, we considered it to be something of a life line in that it enabled us to gain support and to be a part of a community of people also experiencing the challenge of working on a doctorate. We found building online relationships easier by finding out and discussing non-academic parts of our life as well as those relating to our doctoral studies. However, our sense of multiple audiences meant that we self-censored aspects of ourselves. For instance, we avoided tweeting about such trivialities as reality television knowing that it would not enhance our academic profile!

The fear of exposure prevented us from making full use of the potential of the social media. Neither of us blogged about our PhD studies but in hindsight we both wished that we had. We were both anxious about exposing our weaknesses or gaps in our knowledge, as we wanted to present ourselves as knowledgeable experts in our subject area. This is not uncommon. Kirkup (2010) reported that the percentage of academic bloggers is small compared to the number of traditional academic researchers and defined it as 'a minority activity, even amongst those most active in educational technologies' (p. 78). Sue, in particular, felt she suffered from 'imposter syndrome' (Herrmann 2012) generally worrying whether she was clever enough to undertake doctoral study and anxious that she would be found out and ridiculed for even attempting to do a PhD. She was concerned that her writing and research were not good enough or academic enough and thus blogging would be an exposing process. Interestingly, although neither of us blogged about our doctorates, we both felt more comfortable using Twitter and regularly contributed to Twitter's PhD community. We experienced Twitter as a safer medium due to its character length restriction.

Social media have the potential to expose $\mathrm{PhD}$ students' novice status and threaten their standing in their established professional field. For example, using blogging and Twitter to discuss feeling lost, fed up or struggling with aspects of our doctoral studies could threaten the credibility of our expert status in our professional field. In addition, in relation to our doctoral student identity, sharing feelings of despondency online exposed a vulnerability that was not always how we wanted to present ourselves particularly given that our external examiners followed us on Twitter. As Veletsianos (2013) suggests, 'individuals in their research actively managed that presentation to conform to what they perceived others would deem socially acceptable' (p. 649).

\section{Liminality and the doctoral journey}

The process of study has been theorised as transitional by a number of writers. Meyer and Land (2005) use the notion of transition to discuss undergraduates' learning journeys. Similarly, Kiley (2009) applies these notions to undertaking a $\mathrm{PhD}$. Both Meyer and Land (2005) and Kiley (2009) argue that the learning journey involves a transformed sense of identity and both use notions of liminality to theorise this process. Liminality is a term which originates from anthropology where it is used to describe the transitional phase associated with changing state, from the fixed stable state of being to another: for instance, from childhood to adulthood 
(Van Gennup 1960). Turner (1979) identifies three features associated with liminality: a transformation of state, a changing of status, and is accompanied by oscillation that is moving repeatedly between the two stable states. Kiley (2009) refers to two conditions associated with this liminal process, that is, being stuck and mimicry. Stuck is the notion of not being able to move into the transformed new state of being: being stuck in the liminal space. Examples of being stuck include loss of self-esteem or loss of self-confidence. The other aspect of liminality is that of mimicry, the process by which the students copy the desired behaviours of the group to which they aspire.

Associated with the notion of liminality is the idea of threshold concepts which are the critical ideas that mark one's understanding of the discipline and are 'so critical that advanced disciplinary learning is not possible without having crossed the threshold of understanding' (Kiley 2009, p. 297). For PhD studies, Kiley (2009) suggests that there are six threshold concepts: argument or thesis, theory, framework (boundary of research), creation of knowledge, analysis and research paradigm.

We will now apply the notions of identify formation, oscillation, mimicry, being stuck and threshold concepts to our experience of using social media tools for a doctoral study. Our discussion relates our experiences to these constructs and identifies the benefits and challenges of using social media practices to support doctoral studies. We experienced social media tools both as supporting academic identity formation and inhibiting it. When we felt confident, we participated in and contributed to the online community through use of \#phdchat, ${ }^{1}$ and then we (mostly) reaped the benefits of being connected to and challenged by the community PhD students and of developing our academic identity and profile. The social media tools had particular potential to connect us to a vast and 'always connected' audience who we experienced as willing to engage in discussions about our academic area and to overcome the isolation that is typically felt by $\mathrm{PhD}$ students. Our experience is supported by the findings of Mewburn (2011) who has identified the process of talking about the challenges of doctoral study, a notion that she calls 'troubles talk', as an essential part of doctoral student identity formation and argues that it is through 'troubles talk' that the doctoral student experiences the PhD community. She argues that online spaces, such as blogs and Twitter, provide a place for the important aspects of 'performing, managing, displaying and controlling emotional reactions to the exigencies of doctoral study' (p. 330).

On the negative side, when we doubted our abilities and were fearful of being exposed for expressing naive or poorly theorised ideas online, our involvement was limited. Then, we experienced the vastness of the potential audience and the public and permanent nature of the medium as deeply inhibiting. This dichotomy we experienced as an internal tug of war and reflected the oscillation that occurs through the liminal state. Hence, we argue that social media tools provide another set of practices, alongside the private and personal internal oscillations, through which this liminality was experienced. We also argue that the complexity of the multiple audiences available on social media heightens and makes this exposure more acute.

In relation to the process of mimicry in identity formation, social media tools provide a stage on which to act out one's developing identity. For instance, the process of blogging during one's $\mathrm{PhD}$ studies can help to develop both an academic profile and one's skills in academic writing (Kirkup 2010). Similarly, involving oneself in the \#phdchat can be a positive way of experiencing mimicry where one becomes a part of a community of practice learning from others, sharing ideas, learning from others' mistakes, understanding the nature of the PhD process, developing the language of 


\section{Bennett and S. Folley}

being a $\mathrm{PhD}$ student, becoming known as an academic, building relationships with knowledgeable others and knowing how one's discipline operates.

On the other hand, social media tools have the potential to undermine this mimicking process. As we noted above, we were aware of feeling like imposters (Herrmann 2012), of feeling that our participation was just an act and that our knowledge was not adequate. We sometimes felt that our contributions were not an authentic expression of ourselves but instead that we were merely 'trying on language'. These feelings of self-doubt might occur in face-to-face interactions but their character is markedly changed by social media in a way that significantly inhibited our willingness to participate. First, the permanent nature of the interaction exacerbates feelings of exposure. Second, the lack of non-verbal clues makes the interactions more one-dimensional and can lead to misunderstandings. Third, the nature of the connections through social media is different from meeting someone in person: in social media you have a disembodied experience represented by a pseudonym (Twitter usernames sometimes bear no relation to people's real names), so one's relationships often lack an understanding of the other person's background, their personalities, expertise and so on. Hence, we experienced social media as exacerbating our feelings of self-doubt, anxiety and exposure.

In relation to our experience of being stuck, our participation in social media was similarly dichotomous. On the positive side, the support we enjoyed from the online community was tremendous. Indeed, Sue felt so strongly about this that she acknowledged their support in her thesis. Through our online connections, we found ways to work through our experience of being stuck. For instance, it was reassuring to read a blog post discussing paralysis during $\mathrm{PhD}$ studies as normal and typical (Mewburn 2012). However, on occasions we also experienced contributions to \#phdchat as challenging to our developing identity as PhD students. The most notable example was when Sue was participating in \#phdchat synchronous discussion about choice of methodology and someone (who was an experienced $\mathrm{PhD}$ supervisor and whom Sue considered to be knowledgeable) questioned the validity of a case study for a $\mathrm{PhD}$ methodology. In the dialogue taking place on Twitter, the experienced person went so far as to comment that Sue was ignorant and did not know what she was talking about. This obviously affected Sue's confidence and made her question herself and her research. It elicited feelings of being stuck and being unable to traverse the divide into the world of the 'expert researcher'.

Clearly, there is potential for social media to be used in an insensitive and critical way and, as Gregg (2006) notes in relation to receiving critical comments on a blog post, this can be a discomforting and chastening experience and it is the quickest way to have any pretensions of academic work deflated' (p. 155). Whilst this sort of interaction could occur offline, it would not be experienced in the same way, separated from other social cues such as body language. In addition, the nature of the relationship between Sue and 'the expert' would be more tentative as they had only just met, whereas online the intimacy, limited character length and textual nature of the Twitter medium leads to a less guarded and more direct form of communication. Generally, our awareness of the fragility of our identity in relation to doctoral study tended to inhibit our eagerness to participate in activities such as blogging and responding to conversations on Twitter.

Despite the possibility for negative interaction, in general, participation in social media enabled us to develop as $\mathrm{PhD}$ students to understand and navigate the critical threshold concepts that Kiley (2009) identifies (argument or thesis, theory, framework, 
creation of knowledge, analysis and research paradigm). Through participation in social media and exposure to the academic community and to others on the same journey, we learnt about these concepts. For instance, we read blogs written by experienced supervisors about the ways to present one's thesis and were exposed to thinking about theory through reading people's Tweets and blog postings.

\section{Social media practices}

Social media offer relatively new tools in which new scholarly practices are emerging. They offer PhD students both potential and challenge, however they require time to learn how to manage and to incorporate them into scholarly, professional and social practices. Veletsianos (2013) supports this view when he argues that higher education institutions should consider teaching 'sharing' as a scholarly and educational practice in taught programmes particularly at masters or doctoral level. He also recommends that further research should explore the values of networked, digital and open scholars to develop ways to innovate in higher education. Similarly, Lantz-Andersson, Vigmo, and Bowen (2013) found that the use of social media provided extended spaces in which students can interact with others but suggest that these spaces were 'difficult to maintain and have to be recurrently negotiated' (p. 293).

One particularly significant challenge is being able to cope with the distracting nature of social media. It is easy to feel that using social media is time taken away from the study. As Leon and Pigg (2011) suggest in relation to their study of doctoral students' online academic and professional practices:

Their [the participants] digital multitasking allows them to practice employing theoretical concepts in unexpected personal sites while establishing connections and creating professional networks. However, these practices also evoke strong affective responses as graduate students often express guilt or shame about the extent to which these digital practices do not feel like 'work' (p. 3)

One solution to the challenge of the distraction of social media is to try to establish boundaries in the way that one works. Winter et al.'s (2010) study of the characteristics of graduate students in online learning environments found that students often flicked between learning and non-learning activities. The students found themselves distracted by this multi-tasking and developed strategies to create clear boundaries between what was academic and what they considered were non-academic tasks, such as the practice of switching off the non-learning applications. Leon and Pigg (2011) agree, reporting that 'graduate students struggle with the tension between using resources like social media for pleasure and for work' (p. 4).

Our experience suggests a different approach to managing the distracting nature of social media. We tried to develop a disciplined approach to their use by keeping tools running and ignoring anything not related to $\mathrm{PhD}$ work. We used Twitter to provide light relief from the serious work of studying and found comfort in reading tweets from the \#phdchat community carving out time to study on weekends and in the evenings and this helped to reduce isolation and increase our motivation to study. Indeed, Sue developed her participation in the online Twitter community so that she would often make agreements with the online $\mathrm{PhD}$ community (whom she had never met) to work for a while and check back in later. This accountability helped her focus on her $\mathrm{PhD}$ work. Our approach challenges the experience of Winters et al.'s (2010) and Leon and 


\section{Bennett and S. Folley}

Pigg's (2011) students and raises questions about the desirability for scholars to create clear boundaries between the different parts of their lives or boundaries between the task of being a $\mathrm{PhD}$ student and of engaging in online activity. We suggest that there is an alternative way of operating, to welcome the richness and value of online spaces and to integrate use of social media into one's daily practice.

\section{Conclusion}

This paper provides an insider perspective to illuminate emerging practices in relation to the use of social media whilst studying for a doctorate. The paper has analysed the $\mathrm{PhD}$ process as a journey of identity formation and focussed on the ways that social media can support this journey practically, in terms of gaining support from other $\mathrm{PhD}$ students, providing motivation to study and reducing isolation. Our experiences suggest that social media also enable PhD students to enact a developing identity, to learn about critical 'threshold concepts' of doctoral study and to contribute and feel connected to a (generally) supportive international community of doctoral students and as well as to other academic scholars with similar research interests.

The journey of undertaking a doctorate can be made more complex by being in the role of student and also having a professional role. This gives rise to a hybridised identity being both an expert and a novice at the same time. We argue that using social media leads to particular challenges in relation to these multiple identities, in terms of choosing how to present one's self to these multiple audiences. We suggest that this is a new form of online identity formation and management, which is significantly different from offline practice due to the scale and diversity of the potential audiences of social media. As Gergan (2000) notes, social media create a 'multiphrenic' identity, that is, an identity not only created out of a variety of narratives but also performed and presented through a variety of media such as blogs, Twitter and peer-reviewed journals.

We argue that choosing to use social media tools involves developing an online identity at a time when one is also experiencing identity formation in relation to $\mathrm{PhD}$ study and thus adds another layer of complexity to this process. In much of the literature surrounding social media and its potential to support academic studies and academic writing, there is encouragement for increased uptake (Gannon-Leary, Fontainha, and Bent 2011; Gregg 2009; Kirkup 2010; Veletsianos 2012, 2013; Ward and West 2008) and whilst we would echo these, our discussion suggests PhD students require a nuanced understanding of their potential and the challenges raised by their use.

\section{Acknowledgements}

The authors thank Professor Lyn Tett and the journal's reviewers for their support and guidance in the writing of this paper.

\section{Note}

1. \#phdchat is a tag used in tweets on Twitter as a way of collecting posts on the same topic together. \#phdchat is the tag adopted by an emerging community of PhD students to identify posts that might be relevant to other PhD students. Through searching for \#phdchat anyone can read what other students are talking to another about, and also post Tweets containing the \#phdchat tag to contribute to these discussions. In addition, this 
Twitter community of $\mathrm{PhD}$ students held a synchronous discussion on a particular topic one night a week. Topics included literature review, different methodologies, work life balance, reading and writing strategies etc. Thus the use of \#phdchat created a network $\mathrm{PhD}$ students from across the world to provide mutual help and support.

\section{References}

Beijaard, D., Meijer, P. C. \& Verloop, N. (2004) 'Reconsidering research on teachers' professional identity', Teaching and Teacher Education, vol. 20, no. 2, pp. 107-128.

Beldarrain, Y. (2006) 'Distance education trends: integrating new technologies to foster student interaction and collaboration', Distance Education, vol. 27, no. 2, pp. 139-153.

Ellis, C. (2004) The Ethnographic I: A Methodological Novel AboutAutoethnography. AltaMira Press, Walnut Creek, CA.

Ellis, C., Adams, T. E. \& Bochner, A. P. (2010) 'Autoethnography: an overview', Qualitative Social Research, vol. 12, no. 1, [online] Available at: http://www.qualitative-research.net/ index.php/fqs/article/view/1589/3095

Gannon-Leary, P., Fontainha, E. \& Bent, M. (2011) 'The loneliness of the long distance researcher', Library Hi Tech, vol. 29, no. 3, pp. 455-469.

Garrison, D. R., Anderson, T. \& Archer, W. (2000) 'Critical inquiry in a text-based environment: computer conferencing in higher education', The Internet and Higher Education, vol. 2, no. 2-3, pp. 87-105.

Gergan, K. J. (2000) 'The saturated self' in Self and Society, ed. A. Branaman, Blackwell, London, pp. 265-280.

Gregg, M. (2006) 'Feeling ordinary: blogging as conversational scholarship', Continuum, vol. 20, no. 2, pp. 147-160.

Gregg, M. (2009) 'Banal Bohemia: blogging from the Ivory Tower Hot-Desk', Convergence, vol. 15 , no. 4, pp. $470-483$.

Gu, F. \& Widén-Wulff, G. (2011) 'Scholarly communication and possible changes in the context of social media', The Electronic Library, vol. 29, no. 6, pp. 762-776.

Hemsley, J. \& Mason, R. M. (2013) 'Knowledge and knowledge management in the social media age', Journal of Organizational Computing and Electronic Commerce, vol. 23, no. 1/2, pp. $138-167$.

Herrmann, A. F. (2012) "I know I'm unlovable': desperation, dislocation, despair, and discourse on the academic job hunt', Qualitative Inquiry, vol. 18, no. 3, 247-255.

Kiley, M. (2009) 'Identifying threshold concepts and proposing strategies to support doctoral candidates', Innovations in Education and Teaching International, vol. 46, no. 3, pp. 293-304.

Kirkup, G. (2010) 'Academic blogging: academic practice and academic identity', London Review of Education, vol. 8, no. 1, pp. 75-84.

Lantz-Andersson, A., Vigmo, S. \& Bowen, R. (2013) 'Crossing boundaries in Facebook: students' framing of language learning activities as extended spaces', International Journal of Computer-Supported Collaborative Learning, vol. 8, no. 3, pp. 293-312.

Learmonth, M. \& Humphreys, M. (2012) 'Autoethnography and academic identity: glimpsing business school doppelgängers', Organization, vol. 19, no. 1, pp. 99-117.

Leon, K. \& Pigg, S. (2011) 'Graduate students professionalizing in digital time/space: a view from "down delow", Computers and Composition, vol. 28, no. 1, pp. 3-13.

Lewis, S., Pea, R. \& Rosen, J. (2010) 'Beyond participation to co-creation of meaning: mobile social media in generative learning communities', Social Science Information, vol. 49, no. 3, pp. 351-369.

Mewburn, I. (2011) 'Troubling talk: assembling the $\mathrm{PhD}$ candidate', Studies in Continuing Education, vol. 33, no. 3, pp. 321-332.

Mewburn, I. (2012) The Valley of Shit, [online] Avialable at: http://thesiswhisperer.com/2012/ 05/08/the-valley-of-shit/

Mewburn, I. \& Thomson, P. (2013) Why do academics blog? An analysis of audiences, purposes and challenges. Studies in Higher Education, vol. 38, no. 8, pp. 1105-1119.

Meyer, J. H. F. \& Land, R. (2005) 'Threshold concepts and troublesome knowledge (2): epistemological considerations and a conceptual framework for teaching and learning', Higher Education, vol. 49, no. 3, pp. 373-388. 


\section{Bennett and S. Folley}

Orr, K. and Simmons, R. (2010) 'Dual identities: the in-service teacher trainee experience in the English further education sector', Journal of Vocational Education and Training, vol. 62, no. 1 , pp. $75-88$.

Pilkington, R. M. (2009) 'Practitioner research in education: the critical perspectives of doctoral students', Studies in the Education of Adults, vol. 41, no. 2, pp. 154.

Powell, D. A., Jacob, C. J. \& Chapman, B. J. (2012) 'Using blogs and new media in academic practice: potential roles in research, teaching, learning, and extension', Innovative Higher Education, vol. 37, no. 4, pp. 271-282.

Turner, V. (1979) 'Betwixt and between: the liminal period in rites de passage', in Reader in Comparative Religion, eds. W. Less \& E. Vogt, Harper and Row, New York, pp. 234-243.

Van Gennup, A. (1960) The Rites of Passage, Routledge and Kegan Paul, London.

Varpio, L., et al. (2012) Is transferring an educational innovation actually a process of transformation? Advances in Health Sciences Education, vol. 17, no. 3, pp. 357-367.

Veletsianos, G. (2012) 'Higher education scholars' participation and practices on Twitter', Journal of Computer Assisted Learning, vol. 28, no. 4, pp. 336-349.

Veletsianos, G. (2013) 'Open practices and identity: evidence from researchers and educators' social media participation', British Journal of Educational Technology, vol. 44, no. 4, pp. $639-651$.

Vickers, M. H. (2002) 'Researchers as storytellers: writing on the edge-and without a safety net', Qualitative Inquiry, vol. 8, no. 5, pp. 608-621.

Ward, M.-H. \& West. S. (2008) 'Blogging PhD candidature: revealing the pedagogy', International Journal of Emerging Technologies and Society, vol. 6, no. 1, pp. 60-71.

Wikeley, F. \& Muschamp, Y. (2004) 'Pedagogical implications of working with doctoral students at a distance', Distance Education, vol. 25, no. 1, pp. 125-142.

Winter, J., et al. (2010) 'Effective e-learning? multi-tasking, distractions and boundary management by graduate students in an online environment', Research in Learning Technology, vol. 18 , no. 1, pp. 71-83. 